\title{
Use of physical barriers for delayed adjustable strabismus surgery: the effect of Interceed and polyglactin 910 mesh
}

Department of

Ophthalmology, Seoul City Boramae

Hospital, Seoul, Korea J-M Hwang

Department of Ophthalmology, College of Medicine, Seoul National University, Seoul, Korea

B L Chang

Correspondence to: Jeong-Min Hwang, $\mathrm{MD}$, Department of Ophthalmology, Seoul City Boramae Hospital, 395, Sindaebang-2-dong, Dongjak-ku, Seoul 156-012, Korea.

Accepted for publication 24 May 1996

\begin{abstract}
Aims/background-In the course of adjustable strabismus surgery there is only a limited period after surgery before the formation of firm adhesions prevents successful adjustment. To determine if this period could be increased by the interposition of suitable physical barriers, the use of Interceed and polyglactin 910 mesh was investigated in an animal model.

Methods-A total of 39 rabbit eyes were divided into three groups. After recession of the superior rectus muscle (SRM), balanced salt solution was applied to the control group between the free muscle end and the sclera; in each of the two experimental groups, Interceed and polyglactin 910 mesh were applied. Delayed adjustment was performed once on each SRM at 1,2 , or 3 weeks postoperatively. The length and force of the adjustment, the degree of adhesions, and the degree of fibrous proliferation were recorded.

Results-Adjustment was not possible in any of the eyes in the control group. At 1 week postoperatively, adjustment was possible in four out of five eyes with Interceed and in three out of five eyes with polyglactin 910 mesh as a physical barrier.

Conclusions-Interceed may be clinically useful in delaying the timing of adjustment up to 1 week. Further study of the use of other materials could be carried out to see if it was possible to delay the timing of adjustment for more than 1 week. (Br f Ophthalmol 1996;80:759-762)
\end{abstract}

Adjustable suture strabismus surgery can give the surgeon one more chance to modify the amount of surgical correction..$^{1-3}$ Even after placing the eyes in a suitable position with adjustable strabismus surgery, alignment of eyes may drift with time. ${ }^{48}$ Thus, delayed adjustment may be desirable for better postoperative results. ${ }^{910}$ Attempts to delay the adjustment have been made by implantation of silicone and application of mitomycin $\mathrm{C}^{10-12}$ However, silicone can cause discomfort because of its thickness and rigidity and may trigger infection, extrusion, or granuloma formation. Mitomycin C successfully delayed the adjustment by up to 5 weeks, but the accompanying absence of firm reattachment of muscle to the sclera warns against its use. ${ }^{12}$

Interceed is an absorbable fabric composed of oxidised, regenerated cellulose specifically designed as a surgical adjuvant to reduce the formation of postsurgical adhesions. Polyglactin 910 mesh is composed of threads, woven into a mesh with pores. These materials are known to be effective in reducing postoperative adhesions, ${ }^{13}{ }^{14}$ but they have not so far been used as physical barriers for delaying the adjustable strabismus surgery. This experimental study was designed to assess the safety of Interceed and polyglactin 910 mesh extraocularly and their efficacy in delaying adhesion formation and adjustment.

\section{Materials and methods}

Twenty New Zealand white rabbits, weighing $2.0-3.0 \mathrm{~kg}$, underwent $5 \mathrm{~mm}$ recession of the superior rectus muscle (SRM) using double armed 5-0 Dacron (Alcon Surgical Inc, Fort Worth, TX, USA) adjustable suspension sutures. General anaesthesia was achieved by intramuscular injection of $30-45 \mathrm{mg} / \mathrm{kg}$ ketamine hydrochloride (Ketara, Yuhan, Kunpo, Korea) and 5-10 mg/kg xylazine hydrochloride (Rompun, Bayer Vetchem, Korea); for topical anaesthesia, proxymetacaine (proparacaine) hydrochloride (Alcaine, Alcon-Couvreur, Belgium) was used. As physical barriers, balanced salt solution (BSS, Alcon, Fort Worth, TX, USA), Interceed (TC7, Johnson \& Johnson Medical Inc, Arlington, TX, USA), and polyglactin 910 mesh (Vicryl mesh, Ethicon, Neuilly, France) were used for the control group (group C), and experimental groups I and II, respectively. BSS was applied to 10 eyes, Interceed sleeve to 17 eyes, and polyglactin 910 mesh to 12 eyes. Animals in each group were subdivided into 1,2 , and 3 , where $1=$ adjustment 1 week postoperatively, $2=$ adjustment 2 weeks postoperatively, and $3=$ adjustment 3 weeks postoperatively.

\section{PROCEDURES}

Preoperative surgical antisepsis with polyvinylpyrrolidone-iodine to the eyelids was performed. A limbal peritomy was performed from 10 to 2 o'clock. The SRM was isolated on a Jameson hook and intermuscular connections were dissected. The superior oblique tendon was disinserted and allowed to retract from the surgical field. The SRM was then placed on a double armed 5-0 Dacron suture close to the insertion and disinserted from the globe. BSS solution (about $1 \mathrm{ml}$ ) was applied around SRM in the group C, Interceed sleeve $(24 \times 10 \mathrm{~mm})$ was placed around SRM in 
Table 1 Number of adjustable eyes, tractional force, and length of the adjustment in each group

\begin{tabular}{|c|c|c|c|c|c|}
\hline Group & $\begin{array}{l}\text { Time of } \\
\text { adjustment } \\
\text { (weeks) }\end{array}$ & $\begin{array}{l}\text { Adjustable } \\
\text { (No of eyes) }\end{array}$ & $\begin{array}{l}\text { Not adjustable } \\
\text { (No of eyes) }\end{array}$ & $\begin{array}{l}\text { Force }(g) \\
\text { Mean }(S D)\end{array}$ & $\begin{array}{l}\text { Length (mm) } \\
\text { Mean (SD) }\end{array}$ \\
\hline C-1 & 1 & 0 & 4 & $\star$ & * \\
\hline C-2 & 2 & 0 & 3 & $\star$ & $\star$ \\
\hline C-3 & 3 & 0 & 3 & $\star$ & $\star$ \\
\hline I-1 & 1 & $4 \dagger$ & $1+$ & $65.50(7.19)$ & $2.75(0.50)$ \\
\hline I-2 & 2 & 1 & 5 & 185.0 & 1.0 \\
\hline I-3 & 3 & 0 & 6 & $\star$ & $\star$ \\
\hline II-1 & 1 & 3 & 2 & $160.0(18.33)$ & $1.67(0.58)$ \\
\hline II-2 & 2 & 0 & 4 & $\star$ & $\star$ \\
\hline II-3 & 3 & 0 & 3 & * & * \\
\hline
\end{tabular}

Group C=balanced salt solution; I=Interceed; II=polyglactin 910 mesh.

^Impossible to move the muscle owing to adhesion.

t Adjustability is significantly better in group I- 1 than in C-1 by Fisher's exact test $(p=0.04)$.

group I, and polyglactin 910 mesh $(12 \times 10$ $\mathrm{mm})$, between the sclera and SRM, in group II. Finally, the SRM was recessed $5 \mathrm{~mm}$. A loop handle of 5-0 Dacron suture was made for future traction. The edges of the conjunctival peritomy were approximated with interrupted 8-0 polyglactin sutures. At the end of each procedure, ofloxacin eyedrops and dexamethasone ointment were applied topically and $4 \mathrm{mg}$ of gentamicin was injected in the thigh muscle.

\section{DELAYED ADJUSTMENT}

The rabbits were reanaesthetised using the same regime and each SRM was adjusted once under general anaesthesia 1 (C-1, I-1, II-1), 2 (C-2, I-2, II-2), and 3 weeks (C-3, I-3, II-3) after surgery. A dial tension gauge (DT-50, Teclock, Japan) or push pull gauge (PP-705, 5 $\mathrm{g}, 500 \mathrm{~g}$, Teclock, Japan) was used to grasp the loop handle of the sutures connected to the muscle. The SRM was then moved anteriorly (measured by a Castroviejo caliper) as much as possible, with the force needed to do so registered on the gauge. The force and length of adjustment were recorded and adjustment completed. Animals were sacrificed 3 (C-1, I-1, II-1), 4 (C-2, I-2, II-2), and 5 (C-3, I-3, II-3) weeks postoperatively.

\section{EVALUATION OF ADHESIONS}

At the time of adjustment, the adhesions between the muscle, sclera, and conjunctiva were evaluated and recorded. The adhesions were classified as SRM/C (superior rectus muscle/conjunctiva) or SRM/S (superior rectus muscle/sclera) when located above or below the SRM, respectively. The severity of the adhesions was scored from 0 to 4 , where: $0=$ no adhesion, $1=$ filmy adhesions easily separable with blunt dissection, $2=$ mild to moderate adhesions with freely dissectible plane, $3=$ moderate to dense adhesions with difficult dissection, and $4=$ non-dissectible plane.

\section{OBSERVATION OF ABSORPTION TIME}

At the time of adjustment, the degrees of absorption of Interceed sleeve and polyglactin 910 mesh were observed and recorded.

\section{MEASUREMENT OF DISINSERTIONAL FORCE}

Three, 4, and 5 weeks postoperatively, 4-0 black silk was threaded through the SRM close to the insertion and grasped by the push pull gauge after sacrifice of the rabbit with a $10 \mathrm{ml}$ intravenous injection of thiopentone sodium (sodium pentothal). The push pull gauge then pulled the 4-0 black silk until disinserting the SRM from the sclera. The force necessary to disinsert the operated muscle was measured and recorded in one eye in each group.

HISTOLOGICAL EXAMINATION

The involved tissues were subsequently examined macroscopically and microscopically using haematoxylin and eosin staining. Masson's trichrome staining was also performed to evaluate the degree of fibrous proliferation.

\section{STATISTICAL ANALYSES}

A statistical analysis was performed to ascertain any differences in the adjustability between the control and each experimental group and between the two experimental groups using Fisher's exact test. The length of advancement and the force necessary for advancing the muscles were analysed using Wilcoxon rank sum test. The severity of the adhesions were analysed using Mann-Whitney U test.

\section{Results}

\section{ADJUSTABILITY}

Adjustment was not possible in all 10 eyes in groups C-1, C-2, and C-3 (Table 1). Adjustment was possible in four out of five eyes in group I-1, in three out of five in group II-1, and in one out of six in group I-2. Adjustment was not possible thereafter (Table 1).

Comparing the adjustability, there was a significant difference between groups $\mathrm{C}-1$ and I-1 $(p=0.04)$, otherwise, there was no significant difference $(p>0.05)$.

\section{FORCE AND LENGTH FOR THE ADJUSTMENT}

In group I-1, the average force and length of the adjustment were $65.50 \mathrm{~g}$ and $2.75 \mathrm{~mm}$, respectively; in group II-1, the average force and length were $160.00 \mathrm{~g}$ and $1.67 \mathrm{~mm}$; in group I-2, the force and length of the adjustment of one eye it was possible to adjust were $185.00 \mathrm{~g}$ and $1.00 \mathrm{~mm}$ (Table 1). Comparing the force and length of adjustment between groups I and II, there was no significant difference $(\mathrm{p}>0.05)$.

\section{DEGREE OF ADHESIONS}

The degree of adhesions between SRM and conjunctiva was 2 in two eyes and 3 in two eyes in group C-1, 3 in three eyes in groups C-2 and C-3. The degree of adhesions between SRM and conjunctiva was 1 in four eyes and 2 in one eye in group I-1, 1 in one eye and 2 in one eye and 3 in four eyes in group $\mathrm{I}-2$, and 2 in one eye and 3 in five eyes in group I-3. The degree of adhesions between SRM and conjunctiva was 1 in three eyes, 2 in one eye and 3 in one eye in group II-1, 3 in four eyes in group II-2, and 3 in two eyes and 4 in one eye in group II-3.

The degree of adhesions between SRM and the sclera was 1 in one eye, 2 in one eye and 3 in two eyes in group C-1, 2 in one eye and 3 in two eyes in group C-2 and 3 in three eyes in 
group C-3. The degree of adhesions between SRM and sclera was 0 in three eyes, 1 in one eye and 2 in one eye in group I-1, 1 in one eye, 2 in three eyes, and 3 in two eyes in group I-2, and 2 in three eyes and 3 in three eyes in group I-3. The degree of adhesions between SRM and sclera was 1 in three eyes, 2 in one eye and 3 in one eye in group II-1, 3 in four eyes in group II-2 and 3 in one eye and 4 in two eyes in group II-3.

Comparing the degree of adhesions between the control group and group I 1 week after surgery, the degree of adhesions of group I was lower than that of the control group $(p=0.03)$. Comparing the degree of adhesions between groups I and II 3 weeks after surgery, the degree of adhesions of group I was lower than that of group II $(p=0.04)$. There was no significant difference between the other groups in terms of the degree of adhesions ( $p>0.05)$. OBSERVATION OF ABSORPTION TIME

At 1 week postoperatively, Interceed remained in three out of five eyes. Thereafter, it could not be observed. Polyglactin 910 mesh remained in each eye until 3 weeks after surgery.

DISINSERTION FORCE

In control group the disinsertional forces were $340,350,460 \mathrm{~g}$ at 16,18 , and 20 weeks after surgery, respectively. In group I the disinsertional forces were $185,315,380 \mathrm{~g}$ at 3,4 , and 5 weeks after surgery, respectively. In group II the disinsertional forces were $210,380,500 \mathrm{~g}$ at 3,4 , and 5 weeks after surgery, respectively.

HISTOLOGICAL EXAMINATION

There was lymphocyte infiltration and some fibrosis around the muscle. Parts of polyglactin mesh remained in group II.

\section{Discussion}

Delayed adjustment may provide a better chance for the surgeon to align the eyes, ${ }^{9}{ }^{10}$ but postoperative adhesion prevent delayed adjustment. Many types of material have been tested in attempts to prevent reformation of adhesions following strabismus surgery, usually acting as mechanical barriers rather than delaying adjustment. These materials have included tissue implants such as amnioplastin, egg membrane, Tenon's capsule, and peritoneum, and plastic implants such as polyester film, polyvinylidene chloride, and silicone. ${ }^{10112021} \mathrm{Su}$ pramid caps, Supramid muscle sleeves, or polyglactin mesh sleeves, placed over extraocular muscles to function as muscle capsules, have also been tried. ${ }^{14}{ }^{20}{ }^{21}$ However, the results of these studies did not definitively demonstrate that these materials reduce adhesion.

An effective, non-reactive absorbable sleeve would seem to be desirable and to be preferable to a non-absorbable device, which may trigger infection, extrusion, or granuloma formation. Absorbable material, however, has several drawbacks, including a lack of proved effectiveness, lack of Federal Drug Administration approval for use around the eye, and large pore sizes. The pore sizes permit access of blood and tissue fluids with subsequent fibroblastic proliferation and scar formation.
The authors tried absorbable material, Interceed and polyglactin 910 mesh, as physical barriers to delay adjustment.

Interceed was redesigned Surgicel in order to provide a material that could cover traumatised tissues and act as a barrier to the formation of adhesions. Preclinical studies with Interceed demonstrated that it promoted negligible tissue response, was completely absorbed from the peritoneal cavity in less than 28 days, and reduced the extent and severity of post surgical adhesions in standardised animal models. ${ }^{22}$ Although Yaacobi et $a l^{23}$ reported that the use of Interceed sleeves significantly increased formation of postoperative adhesions, they speculated that failure of Interceed to prevent postoperative adhesions may have been due to the presence of some blood in the surgical field. To obtain maximum benefit, it is essential to achieve complete haemostasis before applying Interceed.

Polyglactin 910 mesh is composed of colourless thread, $145 \mu \mathrm{m}$ in diameter, woven into a mesh with pores of $400 \mu \mathrm{m} \times 400 \mu \mathrm{m}$. This mesh was initially employed in abdominal and thoracic surgery to reconstruct deficient abdominal and thoracic wall structures, to repair ruptured visceral organs, and to prevent intraabdominal and intraperitoneal adhesions. Its absorption time ranged from 3 to 8 weeks in these cases. Sondhi et al observed that it reduced postoperative adhesions significantly under conditions of normal surgical trauma. ${ }^{14}$ With these factors in mind we thought Interceed and polyglactin 910 mesh would be the suitable absorbable materials to delay the adjustment; to our knowledge, they have not been used before for this purpose.

Interceed was successful in deferring adjustment until 1 week after the surgery compared with the control group $(p=0.04)$. Interceed also resulted in significantly fewer adhesions 1 week postoperatively than BSS $(p=0.03)$. However, polyglactin 910 mesh failed to delay the adjustment significantly. As a mechanical barrier, there was no significant difference between these materials in terms of adjustability, the length and force for the adjustment, the degree of fibrous proliferation, and the degree of adhesion at 1 and 2 weeks postoperatively. However, at 3 weeks postoperatively there were significantly fewer adhesions with Interceed than with polyglactin 910 mesh $(p=0.04)$. In conclusion, Interceed showed promise as a means of delaying the formation of adhesions and timing of adjustment in extraocular muscle surgery as late as 1 week.

1 Jampolsky A. Strabismus reoperation techniques. Trans Am Acad Ophthalmol Otolaryngol 1975;79:704-17.

2 Jampolsky A. Adjustable strabismus surgical procedure. Symposium on Strabismus. Transactions of the New Orleans Academy of Ophthalmology. St Louis: Mosby, 1978:321-49.

3 Jampolsky A. Current techniques of adjustable strabismus surgery. Am f Ophthalmol 1979;88:406-18.

4 Rosenbaum AL, Metz HS, Carlson M, Jampolsky A. Adjustable rectus muscle recession surgery. A follow-up study. Arch Ophthalmol 1977;95:817 sur.

5 Cassin B, Serianni N, Romano P. The change in ocular alignment between the first day and six weeks following eye alignment between the first day and six weeks foll

6 Clorfeine GS, Parker WT. Adjustment sensitivity of horizontal rectus muscles in adjustable strabismus surgery. Arch Ophthalmol 1987;105:1664-6. 
7 Keech RV, Heckert RR. Adjustable suture strabismus surgery for acquired vertical deviations. $\mathcal{F}$ Pediatr Ophthal mol Strabismus 1988;25:159-63.

8 Chow PC. Stability of one-stage adjustable suture for the correction of horizontal strabismus. Br $\mathcal{F}$ Ophthalmol 1989 73:541-6.

9 Howard CW, Smith AG. Use of adjustable sutures: a helpful modification. Ann Ophthalmol 1986;18:70-3.

10 Shokida MF. Use of a silicone sheet for delayed adjustable Shokida MF. Use of a silicone sheet for delayed adjustat
strabismus surgery. Ophthalmic Surg 1993;24:486-8.

11 Nemet P, Stolovitch C. Delayed reattachment of extraocular muscles. Binocular Vision 1989;4:23-6.

12 Oh SO, Chang BL, Lee J. Effects of mitomycin C on delayed adjustment in experimental strabismus surgery. Kor Ophthalmol 1995;9:51-8.

13 Interceed (TC7) adhesion barrier study group. Prevention of postsurgical adhesions by Interceed (TC7), an absorbable adhesion barrier: a prospective, randomized multicenter clinical study. Fertil Steril 1989; 51:933-8.

14 Sondhi N, Ellis FD, Hamed LM, Helveston EM. Evaluation of an absorbable muscle sleeve to limit postoperative adhesions in strabismus surgery. Ophthalmic Surg 1987;18 441-3.

15 McNeer KW. Adjustable sutures of the vertical recti. $f$ Pediatr Ophthalmol Strabismus 1982;19:259-64.
16 Pratt-Johnson JA. Complicated strabismus and adjustable sutures. Aust N Z F Ophthalmol 1988;16:87-92.

17 Franklin SR, Hiatt RL. Adjustable sutures in strabismus surgery. Ann Ophthalmol 1989;21:285-9.

18 Lueder GT, Scott WE, Kutschke PJ, Keech RV. Long-term results of adjustable suture surgery for strabismus secondresults of adjustable suture surgery for strabismus second-
ary to thyroid ophthalmopathy. Ophthalmology 1992;99: ary to

19 Laby DM, Rosenbaum AL. Adjustable vertical rectus muscle transposition surgery. $\mathcal{F}$ Pediatr Ophthalmol Strabismus 1994;31:75-8.

20 Dunlap EA. Plastic implants in muscle surgery: a study of the possible use of plastic materials in the management of extraocular motility restrictions. Trans Am Ophthalmol Soc 1967;65:393-470.

21 Dunlap EA. Plastic implants in muscle surgery. Arch Ophthalmol 1968;80:249-57.

22 Linsky CB, Diamond MP, Cunningham T, Constantine B, Linsky CB, Diamond MP, Cunningham T, Constantine B,
Decherney AH, diZerega G. Adhesion reduction in a rabbit uterine horn model using TC-7. F Reprod Med 1987;32:1720.

23 Yaacobi Y, Hamed LM, Kaul KS, Fanous MM. Reduction of postoperative adhesions secondary to strabismus surgery in rabbits. Ophthalmic Surg 1992; 23:123-8. 